\title{
Analysis on the Integration of In-and-out of Physical Education Class in Private Universities in the New Era
}

\author{
Yan-fen Xiao \\ Basic Science Department, Wuchang Shouyi University, Wuhan, Hubei, China
}

\begin{abstract}
The paper discusses the new physical education teaching pattern, that is the integration of in-and-out of physical education class. This new teaching pattern integrates the physical education excellent course, elite class, physical education quality and sports ability tests with the sports competition organization. It also integrates the physical education selective class with the extracurricular sports club and physical education students associations. We hope that this overall physical education concept can adapt to the new trend of physical education teaching patterns in the private universities.
\end{abstract}

Keywords - the private universities, integration of in-and-out of physical education class, physical education class, extracurricular P.E activity, teaching

\section{新形势下民办高校体育教育课内外一体化思路探析}

肖艳芬

武昌首义学院基础科学部，武汉，湖北，中国

摘 要 本文对新形势下民办高校体育教育模式进行探寻性研究, 把课内和课外体育纳入体育教育管理体系, 提出了民办高校课内、外 一体化的体育教育管理模式构想, 通过对体育选项课、理论公选课教学与课外体育专项俱乐部; 体育社团、体育协会等学生自主组 织; 校园精品课程、精英班; 体育竞赛组织; 体育素质与运动能力测试等内容进行“一体化”模式管理的研究, 力求以大体育观提出符 合民办高校实际的和适应教育发展新趋势的民办高校体育教育模式，为相关研究提供参考。

关键词 民办高校；课内外一体化；体育课；课外体育活动；教学

\section{1. 前言}

随着我国素质教育体制变革的深入发展和教育部针对 高校体育工作颁布实施的一系列方针政策活动的贯彻落 实, 高校体育教育的空间跳出了单纯每周 2 课时的局限, 将学生的课外体育活动作为了体育课的重要补充与延伸, 高等学校体育工作更加科学、规范, 逐步确立了课内外、 校内外一体化的体育教育理念。然而, 我们不难发现, 由 于过去对体育课开设目的以及方法、手段的理解过于片 面，一直把竞技体育知识技能的掌握看得过重，把体育必 修课当作是考核学生体育成绩的唯一强制性手段, 一些高 校受这种认识茶毒太深, 导致体育教育的“课内外一体化” 往往流于形式, 特别是民办高校, 因为办学性质、体育教 学理念认识上不足、体育意识淡薄等一些客观和主观的原

湖北省教育厅科学研究计划资助项目 (编号: B2014252)
因，在体育教育观念、教育体制、教育结构、人才培养模 式、教育内容和教学方法方面相对滞后。随着时代的发 展, 新形势下民办高校现行的体育教育指导思想和管理模 式必然受到了冲击，寻找新的、适应时代需求的民办高校 体育教育模式势在必行。本文对新形势下民办高校体育教 育模式进行探寻性研究, 旨在寻求符合现代社会需求和现 代教育步伐的民办高校体育教育管理模式。

\section{2. 民办高校体育教育现状分析}

\section{1 目前存在的问题}

1)在民办高校体育的教学目标上，存在着只抓单纯的 体育技术传授, 抓身体素质提高, 而忽视对体育意识、体 育能力方面的培养。在养成终身体育锻炼的习惯等长远目 标上缺乏可行性。 
2)在课程设置上, 运动项目、技术教材, 乃至教学手 段、方法老套, 没有特色。形成“填鸭式”教学, 教师常常 是“照本宣科”的教, 学生常常是囫图吞苯的学, 忽视了教 学主体一一学生的需求。加之考试只强调技术的掌握和身 体素质优劣等原因, 出现不少学生“喜欢体育运动但不喜 欢体育课” 的尴尬局面, 甚至造成一些学生厌学、惧学, 限制了学生个性和个体潜能方面的发展。

3)在检查学生体育锻炼效果的手段上形式单一。目前 民办高校体育考试是检查学生学习效果的主要手段, 在检 验标准设置上, 存在着注重技术掌握程度、身体素质的成 绩, 而忽略对体育的参与、体育能力的检查, 考试的内容 范围不能充分体现高校体育目的任务内涵, 不能全面的反 映出高校体育的目的任务, 形式上基本局限于以“技评”和 “达标”成绩为主的评价。而忽视了对学生体育教育的整体 效果, 包括体育观念、运动能力、意志品质、心理变化等 方面的检查评估。现行的考试制度完全是应试教育结果的 体现, 高分低能, 应付考试, 为考试而练的情况比比皆 是。

4)高校体育的组成形式分为体育教学、课外锻炼、运 动竞赛、运动训练四种, 民办高校对体育教育的总体目标 不明确, 对体育的组织形式缺乏统筹管理, 对学生参与体 育活动的情况, 进行锻炼的方法和效果都缺乏完善地、行 之有效地评价体系, 使得高校体育缺乏整体性和内在联 系, 不利于高校体育总体目标的实现。

\section{2 影响民办高校体育教育的发展存在一些客观因素}

1)民办高校发展时间比较短, 自身还存在一些问题, 虽然近几年民办高校在学生体育课教学和课外体育活动的 工作中投入了大量的人力、财力, 运动健身场所及设施也 得到了较好地改善, 但与学生对课外活动多样化个性化的 需求相比, 学校体育场馆设施、师资队伍和专项经费方面 仍存在着许多不足。

2) 民办高校的办学性质决定了和普通公办高校学生相 比, 民办高校的学生起点相对较低, 文化底子薄, 学习自 觉性不高, 学习动力不足, 学习方法有待改进。学校的文 化底蕴不足和学风不够严谨, 对通过多手段、全方位发展 学生身体素质等方面的体育意识淡薄, 这些问题给学生身 体素质全面发展和人才成长带来一些消极影响。因此, 培 养学生吃苦耐劳的精神, 提高自我控制能力, 以积极的态 度参与体育和面对体育活动中的挫折和困难, 全面发展学 生良好的体育意识, 形成参与体育活动习惯, 培养全面的 身体和心理综合素质, 是民办高校开展体育教育教学工作 的一个非常重要的组成部分。

\section{3. 构建新形势下民办高校体育教育新模式}

\section{1 课内外一体化体育教育模式理论指导}

1)明确新形势下学校体育新内涵

现代社会的发展改变了人们的观念, 学校体育也被赋 予了新的内涵。体育教育就是运用体育手段在生理、心 理、能力、情感等方面对人进行全方位的培养和发展。高 校体育的目标是增强体质, 掌握体育与保健的基本知识, 提高技能, 锻炼意志, 培养集体主义精神, 增强组织纪律 性, 养成锻炼习惯, 而上述目标只有在参与运动实践过程 中才能得到实现。可以说引导、组织学生参加经常性的体 育活动是实现学校体育目标的关键。

2)提高对课外体育活动的认识

课外体育活动是学校体育的重要组成部分, 它对提高 学生的体育意识、发展个性、培养自我锻炼能力、形成经 常锻炼的习惯、促进身心全面发展有着重要作用。体育课 和课外体育活动是学生接受学校体育教育的两个重要途 径。课外体育活动的开展, 充实了学生的生活, 扩大了学 生的活动领域, 加强了学生与社会的联系, 激发了学生的 兴趣爱好, 培养了学生的开拓精神和创新能力, 促进了学 生的个性发展, 也对学生终身从事体育活动起到了积极的 作用。同时课外体育活动为学生提供了一个实践检验体育 课学习效果的活动条件。有关体育知识技能要靠学生在课 外体育活动中去检验、运用, 勇敢顽强的意志品质、优良 的体育道德作风更需要学生通过在课外体育活动中去磨练 和培养。

3)深入学习 2002 年《纲要》中关于体育课内、外一体 化教学的要求, 与时俱进, 通过学校领导、教师和学生对 体育与健康观念的转变为我们构建新形势下适合民办高校 的新的课内、外一体化体育教育模式奠定了思想基础。

\section{2 课内外一体化体育教育模式构建的指导原则}

1)开发符合民办高校的体育课程资源, 从理论和实践 上把新旧体育课程资源规范整合为符合体育基础课、选项 课、选修课和学生课外体育活动的内容, 提高大学生体育 学习的浓厚兴趣。

2)新的体育课内外教学形式, 突出学生的运动参与过 程, 淡化达标要求, 减轻学生对体育考试的压力, 使学生 参与体育课内外自主运动锻炼的强度、密度有所增加。

3) 以学生为本, 是高校体育课内外“一体化”教学管理 模式的指导思想, 在“一体化”的模式中, 教师要转变职 能, 教师的主导作用要向引导作用转变, 让体育协会或俱 乐部更多地参与教学内容、教学计划以及考核的制定, 使 教学内容、教学计划以及考核与体育协会或俱乐部的课外 
体育锻炼最大程度的兼容, 凸显学生主体的作用, 充分发 挥他们学习的主动性和积极性, 是将消极被动式学习转变 为积极主动式学习的有效方法。

4)“授人以鱼, 不如授人以渔”。利用高校体育课内、 外“一体化”教学管理模式在教学组织形式和时间上的优 势。在课堂教学中强调对掌握技术动作方法, 技术动作运 用方法, 运动负荷方法, 竞赛方法等等加以重点传授。而 到课外体育锻炼时, 学生自主实践课堂教学中重点传授各 种方法, 使学生逐步能运用正确的方法进行自主、有效的 锻炼, 促使他们养成锻炼的习惯。

5)将课堂体育教学和课外体育活动看成一个整体, 形 成大体育观, 强调体育课堂教学和课外体育活动的有机结 合。在课内, 教师按照教学大纲和教学计划进行系统教 学, 为课外体育的开展奠定一定的身体和技术基础, 提供 有关的知识和技能储备。课外体育活动为课内体育学习提 供检验学习效果的检验条件。所以在课外鼓励学生从自身 实际出发, 在保证安全的前提下, 按照自己的意愿, 或加 入体育俱乐部, 体育社团, 或参与校内外各类体育竞赛活 动, 体育表演, 体育文化沙龙等形式多样的体育活动。根 据发展体质的普遍性、特殊性、个体差异性、负荷频度性 原则, 将课堂教学与课外体育活动进行整体设计、组织安 排、考核评价和管理, 使体育课教学和课外体育活动科 学、有序的紧密结合。

\section{3 课内外一体化体育教育模式构建及管理}

\subsection{1 体育选项课、理论公选课教学形式}

1)体育课内教学包含体育教学的几个基本方面: 运动 参与、运动技能的掌握、体质健康的增强、心理健康培 养、社会能力培养以及健康教育。改革过去体育课内容几 乎全是竞技体育项目的状况, 以人为本, 拓宽了体育课程 设置的思路, 在学校师资力量、体育场馆条件允许的情况 下, 凡是有助于提高学生健康水平, 符合时代特征, 深受 广大青年学生喜爱的体育文化要素, 都可以列入体育课程 体系。

2)民办高校体育课程除开设公共体育课外, 应增设体 育选项课教学, 和理论公选课教学, 并建立开放式的自主 选课制度。学生在全方位了解教师和课程结构类型的情况 下, 根据自己的专长、需要、和兴趣爱好, 选择学习项目 和选择教师。让学生在自己兴趣的驱动下, 积极参与体育 活动。

3)教师在体育课教学中, 除教授运动技能外, 对教学 原理和方法也应适当进行启发式引导和有效地课内师生 间, 学生间的互动体验, 为学生课外体育活动中进行自主 锻炼奠定基础。
4)体育课教学应该全面考虑运动项目的锻炼价值和社 会转移价值, 知识技能在进入社会后的实际运用价值, 可 以为此专门开设体育公选课, 以理论公选课的形式, 教授 学生例如: 健康教育(运动处方理论、营养与健康保健理 论、简单急救措施)、体育专项技战术知识以及裁判、竞 赛组织等内容。

\subsection{2 课外体育专项俱乐部形式}

建立课外体育专项俱乐部, 是多数高校采用的一种更 灵活、更多样化的课外体育活动组织形式, 课外体育专项 俱乐部的建立, 有利于保持体育课堂教学效益的连续性和 延伸性, 有利于实施终身体育教育和全面推进素质教育, 是高校体育一体化教学模式发展的必然趋势。

民办高校可借鉴一些公办院校开设课外专项俱乐部的 经验, 积极创建课外体育俱乐部, 努力为学生创造有利学 生开展课外体育活动的环境, 开拓学校体育空间, 真正使 民办高校体育教育为全民健身事业奠定良好的基础。

1)选择有锻炼价值的体育内容并结合学生的兴趣爱好 和需要, 在课外开设多种项目俱乐部, 并健全各体育俱乐 部的规章制度。体育部对其组织的建立、制定开展活动的 内容与计划、专项师资的配备等方面给予组织安排, 并不 断地进行协调和业务指导。

2)对俱乐部的管理采用“学分制”等富有弹性的方式, 使学生在共同的兴趣爱好甚至水平接近的氛围中学习, 在 单项体育俱乐部的组织形式下进行的体育课外活动, 学生 不再受年级和行政班的束缚, 学习或锻炼计划更具有弹 性, 这样的课内外有机融合, 无疑可促进教与学的双边过 程, 对提高学生学习的积极性、使学生身心得到全面发 展、对学生体育锻炼习惯的养成都将起到积极的作用。

3)改革考试评价体系: 将学生的课外俱乐部参与程 度、体育能力、体育行为、运动水平等纳入考核体系。在 “一体化”模式中应采用结构性考试, 减少技术技能性指 标，增加“参与行为”和“自我评价”体系指标。将参与体育 俱乐部锻炼的量(包括授课式锻炼和自主式锻炼)与成绩挂 钩, 变应试教育中的注重结果(分数)的学习方式为注重参 与体育锻炼过程的素质教育的学习方式。

\subsection{3 体育社团、体育协会等学生自主组织形式}

1)结合自身的特点, 紧扣当前校园文化建设主题, 积 极展现体育协会、社团的特色。在日常学习生活、体育运 动休闲中广泛开展体育健康知识讲座、培训, 举办各种比 赛(系级赛, 季度排名赛、擂台挑战赛、邀请赛等), 宣扬 体育精神, 弘扬体育文化, 造就健康人才。 
2)体育教师可以通过体育课发现, 培养体育骨干和具 有运动天赋的学生运动员 为大学生体育社团开展课外体育 活动提供人力资源。

3)学校体育社团都由学生处, 团学联等部门主管, 建 立了较系统的组织领导机构模式, 加强社团及其会员管 理, 注重强调社团服务意识与服务质量提高, 积极为社团 活动提供广阔的空间, 使社团得到良好的生存与发展。

4) 注重加强体育职能部门的指导工作, 相关职能部 门提供活动经费保障, 加大宣传力度, 增强校园社团吸引 力。

5）制定合适的学分奖励制度和学时计算制度, 运用 到体育社团的长效发展中。

\subsection{4 校园精品课程、精英班形式}

2003年4月, 教育部发布了《关于启动高等学校教学 质量与教学改革工程精品课程建设工作的通知》精品课程 就是一流教师、一流教学内容、一流教学方法、一流教学 管理等特点的示范性课程。精英班是在这样的理念引导下 组建的一批高水平学生组成的班级。

1)目前高校的体育精品课程以及精英班的设立, 主要 是一些时尚运动课程, 如: 体育舞蹈、街舞、瑜伽、爵 士、啦啦操、跆拳道等, 新兴休闲娱乐课程: 定向越野、 户外拓展、野外生存、滑轮等。民族传统体育项目：舞龙 舞狮、武术等。

2)精英班的开设时间不受学校教务处限制, 由学生自 主选择共同时间段集中上课，一般在时间相对集中的晚上 上课。

3)通过体育精品课程建设和高水平精英班的课程教 学, 拓展体育课程的新视野, 实施特色课程教育教学新方 案, 来优化教学方法、教学条件、手段, 提高学生学习主 动性, 向体育课程要健康, 要效益, 以促进整体教学质量 的提高。

\subsection{5 体育竞赛组织形式}

体育竞赛是学生喜闻乐见的体育活动形式之一, 是学 校课外体育的重要组成部分, 各高校体育部每年已经形成 了体育竞赛的常规, 这种竞赛组织活动对于调动学生参与 体育活动的积极性, 形成良好的群众体育活动氛围, 都有 重要意义。

1)全校性体育竞赛由体育部 (系) 群体中心牵头, 选 择一个院系协办, 在竞赛的组织过程中, 使协办院系更多 地参与和了解体育工作, 支持和配合体育部门的工作, 形 成全校都来关心体育, 全校都来参与体育的良好氛围。

2)除学校每年的传统体育竞赛活动外 (田径、篮球、 足球、排球、羽毛球), 还相应的举办一些休闲、娱乐体
育竞赛活动, 开展各种规模和不同层次相结合的群众体育 竞赛活动, 如: 趣味运动, 定向运动、拓展运动竞赛等, 吸引更多地人参与, 吸引更多地人观摩, 形成课外体育活 动良好的氛围。

3)制定合适的学分奖励制度和学时计算制度, 运用到 课外体育竞赛的长效发展中。

\subsection{6 体育素质与运动能力测试形式}

体育素质及运动能力测试主要是大学生身体素质监 测, 用于按照大学生体质锻炼标准评价其体质状况, 为大 学生进一步锻炼身体, 增强体质提供科学的数据依据, 受 教育部, 学校及体院部门的重视, 测试范围覆盖大学四个 年级, 每个学年。

另外还有裁判员和等级运动员测试, 为有能力的大学 生提供参与较高层次的体育活动的资格晋升提供机会。

\section{4. 总结}

综上所述, 课内外一体化体育教育模式涉及到“课内” 和“课外”两大部分, 这两部分的总体教学目标是一致的, 都是为了全面增进学生的健康。这两部分课程的结构、内 容和组织形式不尽相同。民办高校体育教学应拓展新思 路, 建立新模式, 树立“课内外一体化”的大体育教学观 念。把课内和课外体育纳入体育课程体系, 将体育选项 课、理论公选课教学与课外体育专项俱乐部形式, 体育社 团、体育协会等学生自主组织, 校园精品课程、精英班, 体育竞赛组织, 体育素质与运动能力测试等内容进行“一 体化”模式管理的研究与实践, 这样, 民办高校体育课的 时间和空间将得到拓展, 有限的体育资源将得到整台并加 以有效利用, 有助于民办高校体育的功能得到最大限度地 发挥, 对探索新的、适应时代需求的民办高校体育课内外 “一体化”体育教育管理模式, 为高校体育改革探索出一条 全新的可持续发展之路有重要的意义。

体育课内外一体化的体育教育模式, 通过体育课与课 外体育活动组织形式相结合, 对学生课外活动, 合理运用 学分奖励制和学时计算制; 对学生体育教育的整体效果, 包括体育观念、运动能力、意志品质、心理变化等方面的 检查评估形成标准化和机制化，使体育教学与锻炼更具有 弹性, 有效的调动学生学习和参与体育的积极性和主动 性, 也充分发挥教师的专长, 能更好地因材施教, 也有利 于学生体育习惯的养成。体现了以人为本的理念, 符合高 校体育的发展的方向, 有利于高校体育总体目标的实现。

总之，民办高校应把“课内外体育活动模式”当作系统 工程来研究和设计, 使其为学校体育工作发挥更大的作 用。 


\section{参考文献(References)}

[1] Ministry of Education. The syllabus for the teaching of physical education curriculum in the national colleges and Universities. [2002].

[2] Li Jiakui. On the construction of physical education curriculum model. Journal of Nanjing Institute of Physical Education. 2003.

[3] Chen Tianxia. The study on the effect of the curriculum mode of the in- and- out of PE course. Journal of Beijing Sport University, 2004, (1).

[4] Wang Jian. Development and reform of Physical Education Curriculum. Wuhan: Huazhong Normal University press, 2003. $110-111$.

[5] Hu Yongnan, Duan Jianzhi. Research on the extracurricular sports clubs in Universities. Journal of Physical Education, 2001, (3): 96-98.
[6] Yang Jianwen, Zhang Huxiang. The feasibility study of the implementation of the extracurricular sports clubs for college students in Lanzhou. Health vocational education, 2005, (23): 126-127. 79-81.

[7] Li Qinghui. Sports association and sports system reform. Journal of Physical Education. 2002, 5.

[8] Yang Xiaohong. The tentative ideas of establishing the integration of college sports activity system. Journal of Physical Education. 2002(5).

[9] Butler, Joy. Starting a majors" club. (university clubs). JOPERD-The Journal of Physical Education, Recreation \& Dance.

[10] Ricardo Montelongo. Student Participation in College Student Organizations: A Review of Literature. Journal of the Indiana University Student Personnel Association 2002 Edition: 50-62. 